IRA-International Journal of Education \& Multidisciplinary Studies

ISSN 2455-2526; Vol.08, Issue 02 (August 2017)

Pg. no. 149-163

Institute of Research Advances

http://research-advances.org/index.php/IJEMS

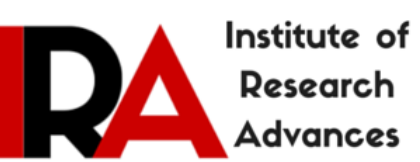

\title{
A Failure to Communicate: Are University Websites Readable?
}

\author{
Zachary W. Taylor \\ orcid.org/0000-0002-6085-2729 \\ Program in Higher Education Leadership \\ The University of Texas at Austin, USA.
}

Type of Review: Peer Reviewed

DOI: http://dx.doi.org/10.21013/jems.v8.n2.p1

How to cite this paper:
Taylor, Z.W. (2017). A Failure to Communicate: Are University Websites Readable?. IRA
International Journal of Education and Multidisciplinary Studies (ISSN 2455-2526), 8(2), 149-
163. doi: http://dx.doi.org/10.21013/jems.v8.n2.p1

(C) Institute of Research Advances.

\section{$(\mathrm{cc}) \mathrm{BY}-\mathrm{NC}$}

This work is licensed under a Creative Commons Attribution-Non Commercial 4.0 International License subject to proper citation to the publication source of the work.

Disclaimer: The scholarly papers as reviewed and published by the Institute of Research Advances (IRA) are the views and opinions of their respective authors and are not the views or opinions of the IRA. The IRA disclaims of any harm or loss caused due to the published content to any party.

Institute of Research Advances is an institutional publisher member of Publishers Inter Linking Association Inc. (PILA-CrossRef), USA. The institute is an institutional signatory to the Budapest Open Access Initiative, Hungary advocating the open access of scientific and scholarly knowledge. The Institute is a registered content provider under Open Access Initiative Protocol for Metadata Harvesting (OAI-PMH).

The journal is indexed \& included in WorldCat Discovery Service (USA), CrossRef Metadata Search (USA), WorldCat (USA), OCLC (USA), Open J-Gate (India), EZB (Germany) Scilit (Switzerland), Airiti (China), Bielefeld Academic Search Engine (BASE) of Bielefeld University, Germany, PKP Index of Simon Fraser University, Canada. 


\begin{abstract}
The readability of university-authored websites is an area wholly unexplored by higher education research and constitutes a crucial gap in the literature. The purpose of this study was to examine the readability of university-sponsored webpages of 30 four-year public American universities ( $n$ $=300$ ), comprising three of the largest university systems in the country. The results suggest that the vast majority of university-authored webpages are unreadable by prospective postsecondary students, and institutions in the same university system wildly vary the readability of their documents. Implications for policy, practice, and future research are addressed.
\end{abstract}

Keywords: higher education, policy, linguistics, language ideologies, first generation students

\title{
Introduction
}

It seems logical to examine the readability of university-authored recruitment, admissions, advising, and financial aid websites and materials to ensure that students from all backgrounds can comprehend what they are reading and successfully apply to our institutions, arrive at our colleges and universities prepared to successfully navigate a postsecondary landscape, and ultimately earn their degrees. Surprisingly, the readability of such documentation is an area wholly unexplored by higher education.

Of higher education research, two of the most important topics and their subsequent implications for postsecondary students emerge: problems of access and equity. "How can the university become more accessible?" (Tierney \& Garcia, 2014) and "How can the university become more equitable?" (Anderson, 2012) are common questions facing university leaders and education policy reformers across the country. However it is possible that the idiolect employed by postsecondary institutions to prospective and current students perpetuates such issues of equity and access: examining the readability of pre-college information could help solve these problems.

After months of researching numerous scholarly databases and academic libraries using the keywords "readability," "readable," and "reading comprehension" in conjunction with "college," "university," "postsecondary," "admission," "advising," "financial aid," and "website," I found no research that examines the readability of university-authored recruitment, admissions, advising, and financial aid materials. This undoubtedly constitutes a gap in the research and begs a critical research question: "To what extent are university websites readable?"

The purpose of this study is twofold. First, I examine if university-authored recruitment, admissions, advising, and financial aid materials - accessed through each institution's ".edu" web domain — are readable by average high school juniors or seniors, equating to the 11th and 12th grade reading levels measured by eight widelyused readability measures. The readability measures include the Automated Readability Index (ARI), Dale-Chall Readability Formula (DC), Flesch-Kincaid Grade Level test (FK), FORCAST Readability Formula (FORCAST), Fry Graph Readability Formula (FRY), Gunning-Fog Index (GFI), SMOG Readability Formula (SMOG), and the Lexile $\mathbb{R}$ Test Measurement (LEXILE). Then, I discuss Rorty'sneopragmatism and Bourdieu's cultural capital theory as they relate to university-authored idiolect and the difficulty for underrepresented students to transcend dominant, linguistic dimensions imposed by the university.

\section{Literature Review}

Although the study of readability and its implications for underrepresented students has been ignored by higher education, diverse researchers have performed foundational readability work for decades.

Readability studies began in the 1920s when educators and research scientists discovered a method of combining diction difficulty with sentence length and structure to predict the readability difficulty of a given text (DuBay, 2004). By the 1950s, writers like Rudolf Flesch, Edgar Dale, and Jean Chall pushed readability formulas into the mainstream and were subsequently used for journalism (Nestvold, 1972), law (Fjeld, 1990), insurance (Walfish\& Watkins, 2005), and other industry standards (Loughran\& McDonald, 2014; Sheehan, 2008). Two of the largest enterprises that have used readability measures heavily are the United States Armed Forces and the healthcare industry. 
Since the 1950s, United States citizens must pass a literacy test to join any branch of the Armed Forces. In the 1970s, a computational error resulted in the recruitment of nearly 200,000 service candidates in the lowest literacy category, but Congress retained them and created workplace literacy programs, leading to the enrichment and subsequent promotion of soldiers (DuBay, 2004). By the mid-1970s, the adoption of readability tests to measure military communication began when the United States Department of Defense began using the Flesch-Kincaid and Dale-Chall measures to compose their communications at an 8th grade reading level (Caylor, Sticht, Fox \& Ford, 1973). Such practices were researched in subsequent years (Office of Naval Research, 1974; Sticht, 1970; Sticht\& Zapf, 1976).

The healthcare field has used readability measures for decades for a variety of purposes (Ley \& Florio, 2007). Recently, healthcare-related readability studies have focused on the wellness documentation received by the patient, such as patient e-communications (Mirsky, Tieu, Lyles \& Sarkar, 2015), privacy policies (Ermakova, Fabian \& Babina, 2015), healthcare guidelines (Meillier, Patel \& Al-Osaimi, 2015), cancer information (Weiss et al., 2016), and healthcare materials integrating with social media (Lopez, Blobel\& Gonzalez, 2016).

In the K-12 arena, given the widespread adoption of the Common Core State Standards (Common Core State Standards Initiative, 2016b) and its suggestions for complex texts through the K-12 spectrum (Common Core State Standards Initiative, 2016a), there has been a plethora of research regarding the readability of K-12 textbooks and curricular materials (Begeny\& Greene, 2014). Yet the study of readability at the postsecondary level is extremely limited to the appropriateness of textbooks selected and used by course instructors. Cline (1973) found that $52 \%$ of students in a community college in mid-Missouri had reading abilities below the grade-level readability of textbooks used in their classes. Shepherd, Selden, and Selden (2011) learned that incoming college students with high ACT reading comprehension scores were not proficient readers of collegiate-level mathematics textbooks. Schneider (2011) found that readability levels of 22 nationally published speech textbooks were written at the 15th grade level, more difficult than a college freshman ought to expect to comprehend. Burton (2014) studied the technical variety of college science textbooks and found that textbooks were not a critical source of student learning, nor did students demonstrate a high level of comprehension when examined. However, Peng (2015) found that a student's age, major, degree plan, and hours worked outside of school were more significant determinants on student performance than the readability of their textbooks through coursework. Ultimately, the last fifty years of postsecondary readability research has focused on one phenomenon of the collegiate experience--textbooks--and little else.

Because literature focused on the readability of university-authored materials does not exist, the following literature reviews separately focus on the underrepresented groups of students who may be most impacted by the level of readability of such documentation.

\section{Students in Poverty}

The negative effects of poverty on brain development, language acquisition, and reading comprehension have been well documented (Boyce et al., 2013; Kolb \& Gibb, 2016; Vernon-Feagans, Garrett-Peters, Willoughby \& Mills-Koonce, 2012).

In a recent study where low socioeconomic status was determined by level of parental higher education, Gullick, Demir-Lira, and Booth (2016) found that low SES children demonstrated a positive relationship in the right hemisphere homologues when performing reading comprehension tasks, indicating that these children engage in more visuospatial processing to replace their lack of verbal processing ability. This is due in part to low SES children experiencing less verbal environments as their brain matures. Here, low SES students biologically adapt to their environments and may struggle to comprehend reading tasks where the verbal elements of a text are dominant at the same levels as their higher SES peers. In short, controlling for parental education variables, the more text a low SES student is exposed to, the less likely they are to comprehend the material to the same degree that their high SES peers do.

Ultimately, a college degree has the transformative power to provide its holder with great upward socioeconomic mobility (Pew Research Center, 2014). Americans most in need of a college education are those occupying lower socioeconomic classes (Stepler, 2016), yet this population is most at risk of lacking the linguistic knowledge and cultural capital to gain college and university admission (Gofen, 2009), and if these students do gain admission, they face hurdles not experienced by their higher SES peers (Thomas, 2014). In addition, low SES 
IRA-International Journal of Education \& Multidisciplinary Studies

students are less likely to have access to high-speed Internet (Holmes, 2016), making it more difficult for them to access pre-college materials than their high SES peers. These studies place low SES students at a distinct linguistic disadvantage compared to their high SES peers.

However, no research exists examining the readability of university websites and its effect on pre-college students in poverty, especially research focused on the cultural capital gained by reading and comprehending precollege materials.

\section{English-Language Learners}

Obstacles facing English-language learners at the postsecondary level are multifarious, ranging from difficulty accessing subject matter (Bifuh-Ambe, 2011), necessity to repeat courses or take remedial coursework (Roessingh \& Douglas, 2012), problems with English composition (Nan, 2012), and underdeveloped vocabulary sets (Lei, Berger, Allen, Plummer \& Rosenberg, 2010).

Wang and Machado (2015) found that most Chinese ELLs do not arrive on campus with polished writing skills and that writing centers at American universities do not meet the needs of Chinese ELLs, constituting a linguistic gap in their knowledge. Karathanos and Mena (2014) argued for an expansion from ELL postsecondary transition programs to an emphasis on providing writing-intensive student support across all disciplines at the university level. Miller, Berkey, and Griffin (2015) lobbied for colleges and universities to provide service-learning opportunities to ELL students as a transition program in order for them to learn English language and culture while attending university classes. Aguirre-Munoz et al. (2006) called for a mode of linguistics preparation when they found that secondary teachers who used academic language fostered ELL students' opportunities to learn (OTLs), which bolstered ELLs understanding of the English language.

However, the bulk of the literature focuses on postsecondary scaffolds during the college experience instead of the readability of pre-college materials for consumption by ELLs. In addition, no research examines readability of university-authored materials as a cultural capital scaffold for ELLs to conquer their linguistic gap and successfully navigate the postsecondary landscape.

\section{First-Generation Students}

First-generation students have been a growing topic of focus for American researchers of higher education because of an increasingly diverse student body on campus and greater numbers of first-generation students attending postsecondary institutions (Ward, Siegel \& Davenport, 2012). First-generation students are more likely to come from ethnic minority groups (Choy, 2001), have lower SES (Nunez \& Cuccaro-Alamin, 1998), speak a language other than English at home, and have lower SAT scores than their counterparts (Bui, 2002). A wealth of current research indicates that these first-generation students encounter fundamentally different pre-college hurdles than their counterparts, including but not limited to lack of family, parental, and/or secondary school counselor involvement in pre-college planning (Brooks-Terry, 1988; Fallon, 1997), racial and ethnic societal inequities (Brown \& Burkhardt, 1999), and inadequate academic preparation (Hossler, Schmit \& Vesper, 1999). Low SES, first-generation students face distinct disadvantages upon entering postsecondary institutions, namely inadequate academic preparation and insufficient sources of financial aid (Engle \& Tinto, 2008; Perna, 2006), and misunderstandings about faculty's academic expectations (Collier \& Morgan, 2008). Subsequently, these students have lower persistence and graduation rates than students from families with college-educated parents (Pike \&Kuh, 2005). Yet in the next decade, numbers of first-generation college students will continue to increase (Fry, 2014).

Non-first-generation students with adequate cultural capital who receive significant parental assistance during the application process are more likely to enroll at a four-year institution, and these same students who receive help from both parents and their secondary school with the application process are more likely to graduate than their first-generation peers (Dumais \& Ward, 2010). The parents of non-first-generation students provide their children with the essential knowledge necessary to facilitate successful postsecondary admission, yet first-generation students lack this essential knowledge about the postsecondary landscape, given the minimal educational expectations and planning procedures their cultural capital affords them (Berkner, Horn \& Clune, 2000). Firstgeneration students lack the family capital of their non-first-generation peers, placing them at a distinct disadvantage upon entering a postsecondary institution (Lohfink \& Paulsen, 2005), forcing universities to provide increased

student support services to assist these students once they enroll and attend (Carlson, 2013). This lack of cultural capital contributes to a sense of "college culture shock," which hinders the first-generation student's ability to 
integrate themselves into the postsecondary environment on both academic and social levels (Hsiao, 1992; Tinto, 2012).

However, this body of research ignores the examination of the readability of university-authored recruitment, admissions, advising, and financial aid materials. Given the general lack of cultural capital held by firstgeneration students (Pascarella, Pierson, Wolniak \& Terenzini, 2004), examining the readability of these documents could inform further research regarding access and equity issues — and recruitment and retention efforts - pertinent to postsecondary institutions serving first-generation college students.

\section{Theoretical Framework}

Framing this examination of readability is Rorty (1989), who spoke of the nature of truth as incontrovertibly framed by language, inseparable from the human mind, validated by the activities of human beings whose agency is solely determined by their linguistic resources and abilities. For decades, American universities have wrestled with access and equity issues, yet without modifying the language used to communicate with prospective and current students, universities cannot be surprised when disproportionate numbers of AfricanAmericans (Johnson, 2013), low SES students (Walpole 2003), and students from other underrepresented groups fail to apply in the winter, enroll the following fall, and graduate four years later (Lynch \& Engle, 2010). Furthermore, universities continue to suffer from the same access and equity issues in large part due to an inability to recruit and retain students from underrepresented groups, especially at predominantly white institutions (PWIs) (Palmer, Maramba \& Holmes, 2012). Here, there is a failure to communicate, but up until this point, this failure has not been articulated as a linguistic shortcoming.

Rorty and the neopragmatic tradition reject the notion of the intrinsic property: postsecondary institutions and their properties can only be defined by the language they employ and audiences they choose to address. A Rortian neopragmatic approach, coupled with Bourdieu's cultural capital theory and its relationship with language, could help guide the studies of these postsecondary access and equity issues by framing these difficulties as linguistic obstacles.

Bourdieu's (1986) theoretical insights inform the role of cultural capital in schools, chiefly that the social networks and cultural experiences hold real, capital value which students carry into their postsecondary experiences to varying degrees. This "habitus" - the amount and type of capital resources a student possesses before their postsecondary experience-can determine how successfully or unsuccessfully a student understands the language and discourse structure of the postsecondary environment, i.e. being unaware of who or what a "bursar" is and does and how to pay tuition and fees (Armstrong \& Hamilton, 2015). For Bourdieu, once a student enters the postsecondary environment, the university "doxa" imposes its value hierarchy and assigns each student a value comprised of their collective symbolic capital. In this sense, the university can be conceived as a dominant entity, both powerful in economic and social terms with the ability to bestow cultural capital value upon its constituents: here is where the lack of cultural capital upon entering the postsecondary environment relegates the underrepresented student to the "dominated" stratum. Bourdieu (1994) writes:

It is only when the dominated have the material and symbolic means of rejecting the definition of the real that is imposed on them through logical structures reproducing the social structures and to lift the censorships that it implies.

Here, Bourdieu implicitly summons underrepresented students (the dominated) to reject the reality imposed upon them by the university (the dominant) and lift the censorship (poor access and equity structures) created by the postsecondary social structures which mirror the outside world, and as Rorty (1989) posits, these structures are erected and sustained by the language of the dominant: language stratifies. Underrepresented students, as the dominated, might lack the linguistic capacity to use the university's language in a "determinate situation" (Bourdieu, 1991): application, advising, enrollment, and financial aid processes. Ultimately, colleges and universities may not be speaking an intelligible, equitable language to underrepresented students. Therefore, it is useful to neopragmatically examine the dominant discourse of postsecondary institutions to explore the relationship between such a dominant linguistic domain and the dominated, underrepresented students attempting to transcend their social and cultural capital boundaries to find belonging in a postsecondary environment. 


\section{Method \\ Data}

The data used for this study come from three sources: (1) Institution-specific data extracted from each university's “.edu” domain, current as of October 2016; (2) readability scores calculated by the Readability Studio software suite; (3) Lexile levels calculated by MetaMetrics and the Lexile Analyzer software suite (permission granted by MetaMetrics to reproduce assessment findings in September 2016). The sample included 30 public, fouryear universities, comprising three of the largest state university systems in the United States.

\section{Data Justification}

30 universities were selected for this study based on a number of criteria. First, I wanted to examine institutions from different geographic regions with access to socioeconomically and ethnically diverse populations. Second, I wanted to examine public universities that belonged to the same system, with that system implementing a common, system-wide application for undergraduate students. Finally, I wanted to study the three systems that have received widespread media coverage and notoriety for their economic and political climates over the past decade. All websites were assessed for their readability during the college application season, which normally runs from early fall (September) until winter (December or January, depending on the institution), making each university's web material available in October especially pertinent to a prospective student's decision-making process.

\section{Readability Measures}

This study aims to best triangulate the readability of each webpage by employing a number of industryaccepted, commonly used readability measures in tandem and then averaging their results. In addition, each readability measure is nuanced and examines different semantic elements of text, allowing for both a semantically and syntactically triangulated estimate. The measures and their definitions are listed below.

The automated readability index (ARI).Calculates the grade level of narrative text, examining the average word and sentence length of a given selection of text (Smith \&Senter, 1967); the Automated Readability Index is measured thus: $\mathrm{G}=(4.71 *(\mathrm{RP} / \mathrm{W}))+(0.5 *(\mathrm{~W} / \mathrm{S}))-21.43 ; \mathrm{G}=$ grade level, $\mathrm{W}=$ number of words, $\mathrm{RP}=$ number of strokes (characters and punctuation less sentence terminating punctuation i.e. periods), $\mathrm{S}=$ number of sentences.

The Dale-Chall readability formula $(D C)$. Calculates the grade level of any document based on sentence length and number of unfamiliar words, unfamiliar defined as words that do not appear on the list of 3,000 most common words for seventh and eighth graders (Chall\&Dale, 1995); the Dale-Chall Readability Formula is measured thus: $\mathrm{G}=(0.1579 *(\mathrm{PDW}))+0.0496 * \mathrm{ASL} ; \mathrm{G}=$ grade level, $\mathrm{PDW}=$ percentage of difficult words, $\mathrm{ASL}=$ average sentence length in words.

The Flesch-Kincaid grade level test (FK). Calculates the grade level of technical documents (manuals and forms) based on sentence length and syllable count (Kincaid, Fishburne, Rogers \&Chissom, 1975); the FleschKincaid Grade Level Test is measured thus: $\mathrm{G}=(11.8 *(\mathrm{~B} / \mathrm{W}))+(.39 *(\mathrm{~W} / \mathrm{S}))-15.59 ; \mathrm{G}=$ grade level, $\mathrm{W}=$ number of words, $\mathrm{B}=$ number of syllables, $\mathrm{S}=$ number of sentences.

The FORCAST readability formula (FORCAST). Calculates the grade level of technical documents (manuals and forms) based on numbers of monosyllabic words (Caylor, Sticht, Fox \& Ford, 1973); the FORCAST Readability Formula is measured thus: $\mathrm{G}=20-(\mathrm{M} / 10) ; \mathrm{G}=$ grade level, $\mathrm{M}=$ number of monosyllabic words.

The Fry graph readability formula (FRY). Calculates the grade level of both technical documents and literature of at least three textual samples of at least 100 words in length, analyzing the numbers of sentences in each passage and numbers of syllables in each sentence, which are then plotted on a graph using the sentences and syllables data on the $\mathrm{X}$ and $\mathrm{Y}$ axes (Fry, 1977).

The Gunning-Fog index (GFI). Calculates the grade level of a document based on numbers of sentences and complex words, defined as words that contain three or more syllables with the exception of proper nouns, words made three syllables by adding the inflections "-ed" and "-es," and compound words composed of simpler words (Gunning, 1952); the Gunning-Fog Index is measured thus: $\mathrm{G}=.4 *(\mathrm{~W} / \mathrm{S}+((\mathrm{C} / \mathrm{W}) * 100)) ; \mathrm{G}=$ grade level, $\mathrm{W}=$ number of words, $\mathrm{C}=$ number of complex words, $\mathrm{S}=$ number of sentences. 
The simple measure of gobbledygook (SMOG). Calculates the grade level of any document at least 30 sentences in length based on the number of complex words and total sentences. A complex word is defined as one with three or more syllables, and complex sentences featuring a semicolon should be counted as two sentences (McLaughlin, 1969); the SMOG Formula is measured thus: $\mathrm{G}=\mathrm{C}$ per 30 sentence passage; $\mathrm{G}=$ grade level, $\mathrm{C}=$ number of complex words (three syllables or more).

The Lexile text measure (LEX). Calculates the grade level of any document based on word frequency and sentence length. The word frequency of a given document is cross-referenced with a proprietary textual database that helps determine how difficult or familiar a word might be for a student grades kindergarten through twelve, with no explicit grade level ceiling. It is also important to note that when Lexile measures and the Lexile scale were developed, a 75\% comprehension rate was used. For instance, if a student with a Lexile of 600L reads a text set at $600 \mathrm{~L}$, it is expected that the student will be able to read and comprehend $75 \%$ of the text (MetaMetrics, 2007). The use of Lexile levels for this study's purpose is validated by their adoption and inclusion in the Common Core State Standards as a method of assigning appropriate texts to students throughout the K-12 spectrum (MetaMetrics, 2016a); the Lexile Test Measure is measured thus: Theoretical Logit $=(9.82247 *$ LMSL) $(2.14634 *$ MLWF $)$ constant where:LMSL $=\log$ of the mean sentence length, MLWF = mean of the log word frequencies; LMSL and MLWF are used as proxies for syntactic complexity and semantic demand. The logits anchored in the equation above translate into Lexiles with the following formula: Lexile calibration $=(\operatorname{logit}+3.3) * 180+200$ (Burdick \& MetaMetrics, 2010).

\section{Methodology}

To answer my research question - “To what extent are university websites readable?"-I needed to examine numerous webpages a prospective student would likely visit during the pre-enrollment "search" period (Hossler\& Gallagher, 1987). This list was formed:

\section{Landing Page (or Home Page)}

Defined as the root ".edu" which features links to a variety of academic and professional departments.

\section{University "Overview" or "About" Page}

Usually authored by the Office of the President or Communications; defined as containing information about the university's geographical location, community, culture, mission and vision, and any notable facts about the university.

\section{Freshman Admission Requirements Page}

Usually authored by the Office of Admissions; defined as outlining the prerequisite coursework, extracurricular involvement, test submissions, and personal background necessary to gain admission.

\section{Application/Apply Page}

Usually authored by the Office of Admissions; defined as including information about application fees, deadlines, requirements, and an overview of the application process from the student perspective.

\section{Financial Aid Home Page}

Usually authored by the Office of Financial Aid; defined as including information regarding financial aid, scholarships, grants, loans, and other forms of financial assistance.

\section{Scholarships Page}

Usually authored by the Office of Admissions or Financial Aid; defined as including a list of institutional and local scholarships, their eligibility requirements, and how to apply.

\section{Cost of Attendance Page}

Usually authored by the Office of Financial Aid; defined as including a table or list of tuition and fees based on residency, as well as information about tuition reciprocity programs (if applicable) fee structures, and estimated costs of books, dining plans, housing, and personal expenses. 


\section{Undergraduate Course Catalog}

Usually authored by the Office of the Registrar or Academic Affairs; defined as a PDF or interactive webpage that lists the courses, majors, degree plans, and departments of the university, along with the student honor code and a variety of undergraduate academic guidelines.

\section{Majors/Degrees Page}

Usually authored by the Office of the Registrar or Academic Affairs; defined as including a list of majors and degree plans available to undergraduate, as well as the major's designation (ex. B.A., B.S., B.B.A.).

\section{Housing/Campus Living/Residence Life Page}

Usually authored by the Office of Housing, Student Life, or Residence Life; defined as including information about on-campus housing, dining plans, and their application processes.

\section{Website Selection Rationale}

Without prior research for reference, I focused on these ten webpages for three reasons. First, by evaluating ten different webpages, usually authored by different offices and/or departments on each website (Admissions, Financial Aid, Student Life, Registrar, etc.), the readability scores indicate the average level of writing produced by multiple stakeholders in a university system. Second, by evaluating webpages most likely to contain information directly relevant to first-year students and not faculty, graduate students, or researchers, these webpages serve as the "face" of university communication as it addresses students from all backgrounds and university standings. Third, since these ten webpages did not exist in identical forms across different university websites, I used similar webpages that all 30 universities included on their websites; many of them exact matches when performing a general Google search (Georgas, 2014). In order for a webpage to be examined in a certain category (i.e. Freshman Admission Requirements), it needed to feature certain common elements that all webpages featured. For example, every "Freshman Admission Requirements" webpage for all 30 universities featured an inventory prerequisite coursework and the test score submissions necessary for admission consideration. A list of all 300 webpages examined in this study and their dates of access can be provided upon request.

\section{Limitations}

Thousands of four-year colleges and universities exist in the United States, therefore, the size of the sample is limiting. Furthermore, my ability to measure the readability of a larger sample of webpages was hindered by the time-intensive process of the data collection. Also, the readability software I used-Readability Studio-was the most efficient, all-encompassing readability software package available, but set maximum scores of the ARI (19), Flesch-Kincaid (19), Fry (17), Dale-Chall (16), and SMOG (19). This means that some text was written at higher levels, but the text was scored at the maximum for these measures.

Certain webpages, such as those focused on athletics, co-curriculars, and honors programs, would have been useful additions to the study and represent areas for further research. However, there is no readability measure unique to university communications, as the eight measures used in this study were created and implemented by other forms of industry. 
IRA-International Journal of Education \& Multidisciplinary Studies

Findings Table 1.

The results from the readability measures aggregated by system, school, and total sample can be found in

Table 1: Average Grade Level Readability of University Webpages ${ }^{1}$

\begin{tabular}{|c|c|c|c|c|c|c|c|c|c|c|c|}
\hline Sys/Sch & $\underline{\mathrm{LP}^{2}}$ & FREQ & $\underline{\text { FAP }}$ & $\underline{\mathrm{CC}}$ & $\underline{\mathrm{APP}}$ & $\underline{\mathrm{SCH}}$ & $\underline{\mathrm{COA}}$ & $\underline{\text { MAJ }}$ & $\underline{\text { HOUS }}$ & OVER & $\mathrm{AVG}_{\text {. }}$ \\
\hline$\overline{\mathrm{A} 1}$ & 13.5 & 9.1 & 12.1 & 15.4 & 8.3 & 13.0 & 10.0 & 7.0 & 15.6 & 15.3 & 11.9 \\
\hline A2 & 14.2 & 12.3 & 14.2 & 15.5 & 11.2 & 15.4 & 14.3 & 11.7 & 9.9 & 12.9 & 13.2 \\
\hline A3 & 12.8 & 15.4 & 12.3 & 15.6 & 15.2 & 14.7 & 11.6 & 15.8 & 12.3 & 15.2 & 14.1 \\
\hline A4 & 15.1 & 12.1 & 11.7 & 16.9 & 13.9 & 13.6 & 9.8 & 13.5 & 11.0 & 14.7 & 13.2 \\
\hline A5 & 12.9 & 13.1 & 10.6 & 15.5 & 12.9 & 14.5 & 11.5 & 14.6 & 11.1 & 12.0 & 12.9 \\
\hline A6 & 13.9 & 11.5 & 13.5 & 15.4 & 12.6 & 12.0 & 12.0 & 13.4 & 15.5 & 13.6 & 13.3 \\
\hline A7 & 14.8 & 11.4 & 12.5 & 15.1 & 13.5 & 14.1 & 13.0 & 13.1 & 12.6 & 15.2 & 13.5 \\
\hline A8 & 10.1 & 15.7 & 12.9 & 15.9 & 9.6 & 12.9 & 10.1 & 10.0 & 14.8 & 15.4 & 12.7 \\
\hline Sys. A - Avg: & 13.4 & 12.6 & 12.5 & 15.7 & 12.2 & 13.8 & 11.5 & 12.4 & 12.9 & 14.3 & 13.1 \\
\hline B1 & 10.1 & 10.3 & 10.4 & 16.3 & 10.8 & 12.6 & 13.5 & 11.3 & 11.6 & 10.6 & 11.8 \\
\hline B2 & 8.0 & 9.3 & 11.9 & 15.3 & 9.9 & 17.1 & 14.2 & 12.2 & 7.2 & 13.8 & 11.9 \\
\hline B3 & 12.4 & 14.5 & 10.3 & 13.6 & 11.0 & 14.2 & 15.6 & 13.3 & 11.9 & 12.1 & 12.9 \\
\hline B4 & 12.5 & 12.3 & 10.9 & 15.1 & 12.7 & 14.1 & 15.0 & 16.1 & 12.0 & 11.7 & 13.2 \\
\hline B5 & 11.9 & 11.4 & 10.4 & 12.1 & 10.5 & 13.1 & 15.4 & 10.3 & 12.6 & 10.0 & 11.8 \\
\hline B6 & 15.7 & 12.6 & 11.4 & 12.1 & 14.4 & 10.8 & 11.8 & 16.1 & 7.3 & 13.5 & 12.6 \\
\hline B7 & 11.6 & 15.0 & 10.8 & 17.7 & 13.4 & 14.2 & 13.9 & 13.2 & 9.4 & 14.3 & 13.4 \\
\hline B8 & 11.3 & 14.7 & 16.7 & 17.1 & 15.0 & 14.0 & 16.4 & 15.9 & 15.7 & 12.8 & 15.0 \\
\hline B9 & 12.6 & 15.3 & 9.9 & 11.9 & 12.2 & 14.9 & 12.8 & 17.4 & 9.6 & 11.9 & 12.9 \\
\hline B10 & 10.4 & 12.5 & 14.2 & 17.5 & 15.0 & 11.6 & 14.0 & 18.0 & 16.3 & 17.0 & 14.7 \\
\hline B11 & 10.4 & 13.1 & 10.4 & 13.9 & 10.2 & 13.8 & 15.5 & 14.4 & 9.0 & 15.8 & 12.7 \\
\hline B12 & 10.2 & 12.7 & 9.6 & 15.5 & 11.5 & 12.3 & 12.5 & 16.9 & 10.7 & 11.0 & 12.3 \\
\hline B13 & 14.0 & 14.2 & 10.1 & 11.3 & 14.4 & 13.7 & 12.2 & 16.9 & 11.4 & 14.7 & 13.3 \\
\hline Sys. B - Avg: & 11.6 & 12.9 & 11.3 & 14.6 & 12.4 & 13.6 & 14.1 & 14.8 & 11.1 & 13.0 & 12.9 \\
\hline $\mathrm{C} 1$ & 11.6 & 9.3 & 10.3 & 12.1 & 9.3 & 10.2 & 11.5 & 11.1 & 10.7 & 9.6 & 10.6 \\
\hline $\mathrm{C} 2$ & 15.4 & 13.4 & 13.7 & 15.6 & 9.8 & 10.6 & 13.1 & 15.0 & 9.3 & 11.6 & 12.8 \\
\hline $\mathrm{C} 3$ & 10.4 & 16.2 & 11.5 & 15.4 & 10.6 & 14.6 & 14.8 & 9.9 & 10.5 & 10.8 & 12.5 \\
\hline $\mathrm{C} 4$ & 10.9 & 13.2 & 12.1 & 13.8 & 8.7 & 14.1 & 13.4 & 12.5 & 7.8 & 14.7 & 12.1 \\
\hline C5 & 14.1 & 11.9 & 13.7 & 13.6 & 13.1 & 13.5 & 14.4 & 11.3 & 12.4 & 14.4 & 13.2 \\
\hline C6 & 16.5 & 12.1 & 10.6 & 13.8 & 8.8 & 15.7 & 9.9 & 15.7 & 7.2 & 13.3 & 12.4 \\
\hline $\mathrm{C} 7$ & 9.8 & 10.6 & 11.6 & 15.4 & 9.9 & 12.7 & 12.6 & 12.1 & 11.2 & 9.5 & 11.5 \\
\hline $\mathrm{C} 8$ & 11.7 & 13.9 & 8.4 & 15.4 & 11.1 & 13.7 & 13.9 & 10.6 & 12.7 & 13.4 & 12.5 \\
\hline C9 & 12.1 & 9.2 & 11.0 & 17.1 & 9.2 & 11.2 & 12.3 & 14.8 & 11.5 & 12.0 & 12.0 \\
\hline Sys. C - Avg: & 12.5 & 12.2 & 11.4 & 14.7 & 10.1 & 12.9 & 12.9 & 12.6 & 10.4 & 12.1 & 12.2 \\
\hline
\end{tabular}

The average grade level of all webpages sampled across three systems was 13.1, 12.9, and 12.2. In general, the most difficult pages to read-across all three systems-were the "Course Catalog" (15.7, 14.6, and 14.7 grade

${ }^{1}$ Readability measures ARI, FK, FORCAST, Fry, GFI, LEX, DC, and SMOG.

${ }^{2}$ LP, Landing Page; FREQ, Freshman Admission Requirements Page; FAP, Financial Aid Page; CC, Course Catalog; APP, Application/Apply Page; SCH, Scholarships Page; COA, Cost of Attendance Page; MAJ, Majors/Degrees Page; HOUS, Housing/Campus Living Page; OVER, Overview/About Page 
levels), the "Overview/About Page" (14.3, 13.0, and 12.1 grade levels), and the "Scholarships Page" (13.8, 13.6, and 12.9 grade levels). Of the "Scholarships Page," three schools wrote their pages above the 15th grade reading level (schools A2, B2, and C6), and only three schools wrote their pages at or below the reading level of an average high school junior (B6, C1, and C2 at grade levels 10.8, 10.2 and 10.6). Systems A and B wrote their "Application/Apply" pages at the 12.2 and 12.4 grade reading levels, with only System C composing their webpages below an 11th grade reading level (10.1). Nine institutions wrote their application instructions at a 13th grade reading level or higher (schools A3, A4, A7, B6, B7, B8, B10, B13, and C5), whereas fourteen schools wrote their application instructions at or below the 11th grade reading level.

The wide range of readability scores is notable, especially in-school and in-system. First, the most difficult single page to read was the "Majors/Degrees Page" for school B10, registering at an 18th grade reading level. The same school, B10, wrote their "Landing Page" at a 10.6 grade level, representing a difference of eight grade levels from the "Scholarships Page." School B2 had an even greater disparity between pages, as their "Housing/Campus Living Page" clocked in at the 7.2 grade level, whereas their "Scholarships Page" was written at a 17.2 grade level, a ten full grade levels more difficult to read. In the same system, school B6 wrote their "Scholarships Page" at a 10.2 grade level, seven grade levels easier to read than B2's. This disparity among schools in the same system and pages on the same school website was common.

At the system level, the average grade level difference between the simplest and most difficult page in the same system was 7.8 grade levels for System A, 10.8 grade levels for System B, and 9.9 grade levels for System C. At the school level, the average grade level difference between the simplest and most difficult page was 5.2 grade levels for System A, 6.2 grade levels for System B, and 5.8 grade levels for System C. Overall, the simplest systemwide page to read was the "Cost of Attendance Page" for System A (11.5 grade level), the "Housing/Campus Living Page" for System B (11.1 grade level), and the "Application/Apply Page" for System C (10.1 grade level). The simplest institution-level page was the "Housing/Campus Living Page" for schools B2 and C6, registering and average grade level of 7.2.

\section{Discussion}

My research question was answered: university websites are written at levels too high for high school juniors and seniors of average literacy levels. In addition, as mentioned in the Limitations section of this paper, multiple readability measures were capped at the 16th (Dale-Chall), 17th (Fry), or 19th (ARI, FK, and SMOG) grade reading levels, which means that institutional readability averages are higher than scored. Because these materials are too advanced for most educated juniors and seniors, the online college and university exploration process must be linguistically difficult for illiterate parents, parents and students whose first language is not English, families surviving poverty, and first-generation college students. Considering the importance of high school counselors in the college exploration process (Corwin, Venegas, Oliverez \& Colyar, 2004), their high burnout rates (Bardhoshi, Schweinle \& Duncan, 2014) and overwhelming student caseloads (McDonough, 2005) renders the university website a critical source of pre-college information for aspiring college students from all backgrounds. The readability of university-authored web materials is problematic.

The "Overview/About" page was consistently written at the 13th and 14th grade reading levels across all three systems. Generally, such a page is meant not only for incoming students but also for the general public, as it includes information about the school's connection to community, impact projects in the state and region, short and long term goals, and the school's strategic mission and vision. However, considering the average American reads at the 7th grade level (Walsh \&Volsko, 2008), the 30 schools sampled write their material far beyond the literacy abilities of the average American, averaging at the 14.3, 13.0, and 12.1 grade reading levels. By composing these materials at such difficult reading levels, the universities in this study are severely limiting the ability for younger students to explore college options and better prepare themselves for the postsecondary readiness upon graduation.

Although President Obama's higher education agenda focused on the FAFSA's ease of use (Kanter, 2010) and the difficulty of the FAFSA has been well documented (Douglas-Gabriel, 2016; Glum, 2015; Prete, 2013; US Department of Education, 2009), this seems to be putting the cart before the horse: the readability of instructions for the standard university application requires examination. Students and their families should be provided simple, straightforward directions on how to complete the application, yet the data suggest even the directions are too complicated. The readability difficulty of application instructions could represent thousands of dollars in lost application revenue for institutions and their systems, but more importantly, underrepresented groups such as 
English-language learners, students in poverty, and first generation students might be facing unnecessary linguistic hurdles on their path toward postsecondary enrollment, success, and graduation.

It is also interesting to note that there seems to be no standardization of readability levels across schools in the same system or departments in the same school: this is another failure to communicate at multiple levels. Given that all three systems use a common "system application," the range of readability levels for the "Freshman Admission Requirements" pages vary from 9.1 to 15.1 in System A, 9.3 to 15.3 in System B, and 9.2 to 16.2 in System C. This phenomenon was common between all institutions in the same system, as the difference between the simplest and most difficult page of institutions in the same system regularly ranged from 5-8 grade levels. Surely, this readability fluctuation between intersystem institutions is confusing for the aspiring in-state student who - due to financial circumstances - can only afford in-state tuition. Compounding this failure to communicate is that only three of the thirty schools sampled write their "Scholarships" page at or below an 11th grade reading level, rendering such information-essential for informed, educated college choice-inaccessible for those of marginalized, underrepresented populations.

In no uncertain terms, the data suggest that university websites are too difficult for high school juniors and seniors of average literacy levels.

\section{Implications for Policy}

In linguistic terms, President Obama's only contribution to higher education was his commitment to simplifying the FAFSA (Kanter, 2010). For Obama, simplifying the language and process of the FAFSA is good for families, and simplifying university websites is good for families, too. Higher education researchers and policy makers must ensure that unintelligible pre-college materials do not perpetuate issues of equity and access: this is a problem that finds its solution in a study of the language and linguistics of higher education. Future higher education policy should dictate that university websites be written at appropriate levels, portraying the university as an accessible, equitable environment free from the linguistic hurdles known by so many underrepresented student populations.

\section{Implications for Higher Education Institutions}

Higher education researchers must turn a mirror upon themselves and call for widespread readability audits of their websites, beginning with an understanding of who has website editing privileges and how those privileges translate into readability of web materials. The data suggest that it is entirely possible that every department in a university setting - Registrar, Financial Aid, Admissions, etc. — writes their webpages differently and at a different level of readability difficulty. Institutional frameworks and standardization guidelines for the readability of web content could solve this problem.

Furthermore, the admissions counselors and advisors who interface with prospective students on a regular basis need to be made aware of the appropriate, grade level communications issued by their university and adjust their language accordingly. Website readability is one issue, but a failure to communicate a consistent, institutionwide message is another. Fortunately, these issues can be remedied and students better served by institutional communication and collaboration when developing recruitment, admissions, advising, and financial aid materials, communication strategies, and university dialogues.

\section{Implications for Further Research}

Given the limited scope of this particular preliminary study, there is a wealth of knowledge to be discovered in the field of higher education language and linguistics. The research questions are interdisciplinary: higher education, informatics, sociolinguistics, and cognitive science are all fields in which require investigation. In terms of cognitive science, the field of higher education needs to ask such questions as, "When, why, and how do pre-college students develop the cognitive ability to process language offered by the university system?" and "How can K-12 counselors and educators provide linguistic scaffolds to facilitate a more efficient cognitive process?" Simply, K-12 stakeholders must ask, "What do students need to know about college?" Considering the intersection of informatics and sociolinguistics, the field must explore such questions as, "How can universities speak and organize information and language in a way that is most intelligible and commonsensical to pre-college students?" and "How can universities make their digital communication as equitable and accessible as possible?" Finally, through a higher education lens, the field needs to investigate such questions as, "Which variables associated with 
higher education culture produces inaccessible language?" and "How can disadvantaged populations break through the glass ceiling of higher education linguistics to access equitable higher education resources?"

\section{Conclusion}

Decades of higher education research has found that underrepresented students already face enough obstruction on their path toward a postsecondary education: readability of pre-college materials should not be a problem, but the data in this study suggest it is.

First, students from underrepresented, marginalized populations must be given the linguistic tools to speak the university's language - or understand its basic tenets - and then engage with that language to explore the plethora of postsecondary institutions available, make informed decisions, and feel linguistically prepared to navigate a college career. In a Rortianneopragmatic sense, this linguistic preparation begins in the secondary school: K-12 teachers and guidance counselors must make the dominant language of the university more accessible. It is entirely possible that if secondary students - and potentially elementary and middle-level students - were exposed to and learned university idiolect, they will be more successful accessing postsecondary education. Here, knowledge of language is power: university idiolect can operate as a representation of a scholarly, prestigious environment, but $\mathrm{K}$ 12 leaders cannot operate under the assumption that such an idiolect is understood by students.

University leaders must finally acknowledge that English-language learners, students in poverty, and firstgeneration college students are at a distinct linguistic disadvantage due to the lack of postsecondary idiolect spoken in the home and in underrepresented, under-supported schools: surely, conversations about unsubsidized loans, matriculation fees, interdisciplinary minors, and other nuances of higher education linguistics aren't topics of discussion at the dinner table: this acknowledgement can be confirmed in the form of simplifying the language of pre-college materials. In a Bourdieuian sense, universities - by dissemination of their idiolect - have positioned themselves as dominant majorities, framing and producing inaccessible language structures that are fundamentally inequitable and discriminatory against said constituencies. So when universities use such complicated, idiosyncratic diction and discourse, university leadership simply cannot be confused as to why underrepresented students are uncomfortable completing the FAFSA or navigating a college application. This gap in linguistic input —created by universities - is only magnified as these underrepresented students struggle to navigate the postsecondary environment and find themselves at a loss when they cannot comprehend simple university procedures, such as how and when to pay tuition and how to navigate a course catalog to understand their own degree program.

When does a student and their family learn what a bursar or registrar is? Surely, a one-day freshman orientation cannot suffice. Can a student define a bachelor's degree? College academic advisors already have caseloads in the hundreds. The language employed by the dominant university finds a home no place else aside from the arena of higher education: where and when will students learn to speak our language? And why we are speaking it in the first place?

\section{References}

[1] Aguirre-Munoz, Z., Boscardin, C. K., Jones, B., Park, J., Chinen, M., Shin, H., Benner, A. (2006). Consequences and validity of performance assessment for English language learners: Integrating academic language and ell instructional needs into opportunity to learn measures. National Center for Research on Evaluation, Standards, and Student Testing, $1-221$.

[2] Ambe-Bifuh, E. (2011). Postsecondary learning: Recognizing the needs of English language learners in mainstream university classrooms. Multicultural Education, 19(3), 13-19.

[3] Anderson, G. M. (2012). Equity and critical policy analysis in higher education: A bridge still too far. Review of Higher Education, 36(1), 133-142.

[4] Armstrong, E. A., \& Hamilton, L. T. (2015). Paying for the party: How college maintains inequity. Cambridge, MA: Harvard.

[5] Bardhoshi, G., Schweinle, A., \& Duncan, K. (2014). Understanding the impact of school factors on school counselor burnout: A mixed-methods study. Professional Counselor, 4(5), 426443.

[6] Begeny, J. C., \& Greene, D. J. (2014). Can readability formulas be used to successfully gauge difficulty of reading materials? Psychology in the Schools, 51(2), 198-215. Berkner, L., Horn, L., Clune, M., \& MPR Associates, Inc. (2000, March). Descriptive summary of 1996-96 beginning postsecondary students: Three years later (Research Report No. 2000-154). 
[7] Bourdieu, P. (1986). The forms of capital. In J. Richardson (Ed.), Handbook of theory and research for the sociology of education (pp. 241-258). New York, NY: Greenwood.

[8] Bourdieu, P. (1991). Language and symbolic power. Cambridge, UK: Polity.

[9] Bourdieu, P. (1994). Structures, habitus, power: Basis for a theory of symbolic power. In N. Dirks, G. Eley, \& S. Ortner (Eds.), Culture/power/history: A reader in contemporary social theory (pp. 155-199). Princeton, NJ: Princeton.

[10] Boyce, L. K., Gilliam, S. L., Innocenti, M. S., Cook, G. A., \& Ortiz, E. (2013). An examination of language input and vocabulary development of young Latino dual language learners living in poverty. First Language, 33(6), 572-593.

[11] Brooks-Terry, M. (1988). Tracing the disadvantages of first-generation college students: An application of Sussman's option sequence model. In S. K. Steinmetz (Ed.), Family and support systems across the life span (pp. 121-134). New York, NY: Springer.

[12] Brown, H. E., \& Burkhardt, R. L. (1999, June). Predicting student success: The relative impact of ethnicity, income, and parental education (Research Report No. HE032343).

[13] Bui, K. V. T. (2002). First-generation college students at a four-year university: Background characteristics, reasons for pursuing higher education, and first-year experiences. College Student Journal, 36(1), 3-12.

[14] Burdick, H., \& MetaMetrics. (2010). The origin of the lexile specification equation. Retrieved from MetaMetrics website:https://lexile-websitemedia2011091601.s3.amazonaws.com/resources/materials/The_Origin_of_the_Lexile_Specification_Equation.pdf

[15] Burton, R. S. (2014). Readability, logodiversity, and the effectiveness of college science textbooks. Journal of College Biology Teaching, 40(1), 3-10.

[16] Carlson, D. (2013). Connection equals retention: Student support services for first-generation college students (Master's thesis).

[17] Caylor, J. S., Sticht, T. G., Fox, L. C., \& Ford, J. P. (1973, March). Methodologies for determining reading requirements of military occupational specialties (Research Report No. 73-5).

[18] Chall, J., \& Dale, E. (1995). Readability revisited: The new Dale-Chall readability formula. Cambridge, MA: Brookline.

[19] Choy, S. P. (2001). Students whose parents did not go to college: Postsecondary access, persistence, and attainment. Retrieved from National Center for Education Statistics website: http://nces.ed.gov/pubs2001/2001126.pdf

[20] Cline, T. A. (1973). Readability of community college textbooks and the reading ability of the students who use them. Journal of Reading Behavior, 5(2), 110-118.

[21] Collier, P. J., \& Morgan, D. L. (2008). "Is that paper really due today?": differences in first generation and traditional college students' understandings of faculty expectations. Higher Education, 55(4), 425-446.

[22] Common Core State Standards Initiative. (2016a). Key shifts in English language arts. Retrieved from http://www.corestandards.org/other-resources/key-shifts-in-english-language-arts/

[23] Common Core State Standards Initiative. (2016b). Standards in your state. Retrieved from http://www.corestandards.org/standards-in-your-state/

[24] Corwin, Z. B., Venegas, K. M., Oliverez, P. M., \&Colyar, J. E. (2004). How appropriate guidance affects educational quality. Urban Education, 39(4), 442-457.

[25] Douglas-Gabriel, D. (2016, March 16). Why it's harder to complete financial aid applications this year. Retrieved from Washington Post website: https://www.washingtonpost.com/news/grade-point/wp/2016/03/16/why-its-harder-tocomplete-financial-aid-applications-this-year/

[26] DuBay, W. H. (2004, August). The principles of readability. Retrieved from ERIC database. (ED490073)

[27] Dumais, S. A., \& Ward, A. (2010). Cultural capital and first-generation college success. Poetics, 38(3), $245-265$.

[28] Engle, J., \& Tinto, V. (2008, November). Moving beyond access: College success for low income, first-generation students. Retrieved from ERIC database. (ED504448)

[29] Ermakova, T., Fabian, B., \&Babina, E. (2015, March). Readability of privacy policies of healthcare websites. Paper presented at Internationale Tagung Wirtschaftsinformatik, Osnabrück, Germany. Retrieved from https://www.researchgate.net/publication/268981590_Readability_of_Privacy_Policies_of_Healthcare_Websites

[30] Fallon, M. V. (1997). The school counselors' role in first generation students' college plans. The School Counselor, 44(5), 384-393.

[31] Fjeld, R. V. (1990). Readability of legislative texts and public information. Meeting of the World Congress of Applied Linguistics, pp. 1-14.

[32] Fry, E. (1977). Fry's readability graph: Clarifications, validity, and extension to level 17. Journal of Reading, 21(3), 242-252.

[33] Fry, R. (2014, October 2). U.S. high school dropout rate reaches record low, driven by improvements among Hispanics, blacks. Retrieved from Pew Research Center website: http://www.pewresearch.org/fact-tank/2014/10/02/u-s-highschool-dropout-rate-reachesrecord-low-driven-by-improvements-among-hispanics-blacks/

[34] Georgas, H. (2014). Google vs. the library (part II): Student search patterns and behaviors when using Google and a federated search tool. Libraries and the Academy, 14(4), 503-532.

[35] Glum, J. (2015, January 7). FAFSA too complicated? Financial aid process should be easier, say experts, politicians. Retrieved from International Business Times website: http://www.ibtimes.com/fafsa-too-complicated-financial-aidprocess-should-be-easier-say-experts-politicians-1776446 
[36] Gofen, A. (2009). Family capital: how first-generation higher education students break the intergenerational cycle. Family Relations, 58(1), 104-120.

[37] Gullick, M. M., Demir-Lira, O. E., \& Booth, J. R. (2016). Reading skill-fractional anisotropy relationships in visuospatial tracts diverge depending on socioeconomic status. Developmental Science, 19(4).

[38] Gunning, R. (1952). The technique of clear writing. New York, NY: McGraw-Hill.

[39] Holmes, A. (2016, May 12). Rich people have access to high-speed Internet; many poor people still don't. Retrieved from The Center for Public Integrity website: https://www.publicintegrity.org/2016/05/12/19659/rich-people-haveaccess-high-speed-internet-many-poor-people-still-dont

[40] Hossler, D., \& Gallagher, K. S. (1987). Studying student college choice: A three-phase model and the implications for policymakers. College and University, 62(3), 202-221.

[41] Hossler, D., Schmit, J., \& Vesper, N. (1999). Going to college: How social, economic, and educational factors influence the decisions students make. Baltimore, MD: Johns Hopkins.

[42] Hsiao, K. P. (1992, November). First-generation college students. In Educational Resources Information Center (Author), ERIC (pp. 1-5).

[43] Johnson, L. (2013). The benefits of a comprehensive retention program for African American students at a predominately white university. Interdisciplinary Journal of Teaching and Learning, 3(1), 38-54.

[44] Kanter, M. (2010). Higher ed in the Obama years. New England Journal of Higher Education, 24(3), 28-29.

[45] Karathanos, K. A., \& Mena, D. D. (2014). Exploring the experiences of linguistically diverse college of education student writers. Journal of University Teaching and Learning Practice, 11(3), 1-13.

[46] Kincaid, J. P., Fishburne, R. P., Rogers, R. L., \&Chissom, B. (1975, February). Derivation of new readability formulas (automated readability index, fog count, and flesch reading ease formula) for Navy enlisted personnel (Research Report No. 8-75).

[47] Kolb, B., \& Gibb, R. (2015). Childhood poverty and brain development. Human Development, 58(4-5), 215-217. http://dx.doi.org/10.1159/000438766

[48] Lei, S. A., Berger, A. M., Allen, B. M., Plummer, C. V., \& Rosenberg, W. (2010). Strategies for improving reading skills among ell college students. Reading Improvement, 47(2), 92-104.

[49] Levine, A. (2008, November 11). Higher education in the age of Obama. Retrieved from Inside Higher Ed website: http://www.insidehighered.com/views/2008/11/10/levine

[50] Ley, P., \& Florio, T. (1996). The use of readability formulas in health care. Psychology, Health \& Medicine, 1(1), 7-28.

[51] Lohfink, M. M., \& Paulsen, M. B. (2005). Comparing the determinants of persistence for first generation and continuing-generation students. Journal of College Student Development, 46(4), 409-428.

[52] Lopez, D. M., Blobel, B., \& Gonzalez, C. (2016). Information quality in healthcare social media - an architectural approach. Health and Technology, 6(1), 17-25.

[53] Loughran, T., \& McDonald, B. (2014). Measuring readability in financial disclosures. Journal of Finance, 69(4), 16431671.

[54] Lynch, M., \& Engle, J. (2010, August). Education Trust: Big gaps, small gaps: Some colleges and universities do better than others in graduating African-American students.

[55] McDonough, P. M. (2005). Counseling and college counseling in America's high schools. Retrieved from National Association for College Admission Counseling website: http://www.nacacnet.org/research/researchdata/Documents/WhitePaper_McDonough.pdf

[56] McLaughlin, G. H. (1969). Clearing the smog. J Reading, 13(3), 210-211.

[57] Meillier, A., Patel, S., \& Al-Osaimi, A. M. (2015). Readability of healthcare literature for hepatitis b and c. Digestive Diseases and Sciences, 60(12), 3558-35562.

[58] MetaMetrics. (2007). The Lexile framework for reading: Implementation resource manual [Pamphlet]. Retrieved from https://www.azed.gov/wp content/uploads/PDF/FAQ_WhatdoestheLMmean.pdf

[59] MetaMetrics. (2016a). Common core standards. Retrieved from The Lexile Framework for Reading website: https://lexile.com/using-lexile/lexile-measures-and-the-ccssi/

[60] MetaMetrics. (2016b). Lexile analyzer. Retrieved from The Lexile Framework for Reading website: https://lexile.com/analyzer/

[61] MetaMetrics. (2016c). Lexile-to-grade correspondence. Retrieved from https://lexile.com/aboutlexile/gradeequivalent/grade-equivalent-chart/

[62] Miller, J., Berkey, B., \& Griffin, F. (2015). International students in American pathway programs: Learning English and culture through service-learning. Journal of International Students, 5(4), 334-352.

[63] Mirsky, J. B., Tieu, L., Lyles, C., \& Sarkar, U. (2016). Readability assessment of patient provider electronic messages in a primary care setting. Journal of the American Medical Informatics Association, 23(1), 202-206.

[64] Nan, F. (2012). Bridging the gap: Essential issues to address in recurring writing center appointments with Chinese ell students. Writing Center Journal, 32(1), 50-63.

[65] Nestvold, K. (1972). Cloze procedure correlation with perceived readability. Journalism Quarterly, 49(3), 592.

[66] Nunez, A., \& Cuccaro-Alamin, S. (1998, June). First-generation students: Undergraduates whose parents never enrolled in postsecondary education. Retrieved from NCES website: http://nces.ed.gov/pubsearch/pubsinfo.asp?pubid=98082 
[67] Office of Naval Research. (1974, May). Improving reading comprehension: Measuring readability (Research Report No. AIR-30801-5-74-FR) (R. P. Carver, Author).

[68] Palmer, R., Maramba, D. C., \& Holmes, S. L. (2012). A contemporary examination of factors promoting the academic success of minority students at a predominantly white university. Journal of College Student Retention, 13(3), 329-349.

[69] Pascarella, E. T., Pierson, C. T., Wolniak, G. C., \&Terenzini, P. T. (2004). First-generation college students: Additional evidence on college experiences and outcomes. Journal of Higher Education, 75(3), 249-284.

[70] Peng, C.-C. (2015). Textbook readability and student performance in online introductory corporate finance classes. Journal of Educators Online, 12(2), 35-49.

[71] Perna, L. W. (2006). Studying college access and choice: A proposed conceptual model. In J. C. Smart (Ed.), Higher education: Handbook of theory and research (Vol. 21, pp. 99-157).

[72] Pew Research Center. (2014, February 11). The rising cost of not going to college. Retrieved from Pew Research Center website: http://www.pewsocialtrends.org/2014/02/11/therising-cost-of-not-going-to-college/

[73] Pike, G. R., \&Kuh, G. D. (2005). First- and second-generation college students: A comparison of their engagement and intellectual development. Journal of Higher Education, 76(3), 276-300.

[74] Prete, N. (2013). FAFSA difficulties discourage some students from applying for aid. Retrieved from Scripps Howard Foundation Wire website: http://www.shfwire.com/node8382/

[75] Roessingh, H., \& Douglas, S. R. (2012). Educational outcomes of English language learners at university. Canadian Journal of Higher Education, 42(1), 80-97.

[76] Rorty, R. (1989). Contingency, irony, and solidarity. Cambridge, UK: Cambridge.

[77] Schneider, D. E. (2011). Assessing the readability of college textbooks in public speaking: Attending to entry level instruction. Communication Teacher, 25(4), 246-255.

[78] Sheehan, K. (2006). Consumer friendly or reader hostile? An evaluation of the readability of DTC print ads. Health Marketing Quarterly, 23(4), 1-16.

[79] Shepherd, M. D., Selden, A., \& Selden, J. (2011, April). Possible reasons for students' ineffective reading of their firstyear university mathematics textbooks (Research Report No. 2011-2).

[80] Smith, E. A., \&Senter, R. J. (1967). Automated readability index. AMRL TR, 1-14.

[81] Stepler, R. (2016, February 24). Hispanic, black parents see college degree as key for children's success. Retrieved from Pew Research Center website: http://www.pewresearch.org/facttank/2016/02/24/hispanic-black-parents-seecollege-degree-as-key-for-childrens-success/

[82] Sticht, T. G. (1970, October). Literacy demands of publications in selected military occupational specialties (Research Report No. 25-70).

[83] Sticht, T. G., \& Zapf, D. W. (1976, September). Reading and readability research in the armed forces (Research Report No. 76-4).

[84] Thomas, G. (2014). Closing the policy-practice gap for low-SES students in higher education: The pedagogical challenge. Higher Education Research \& Development, 33(4), 807-820.

[85] Tierney, W. G., \& Garcia, L. D. (2014, October). Getting in: Increasing access to college via mentoring, findings from 10 years of a high school mentoring program.

[86] Tinto, V. (2012). Leaving college: Rethinking the causes and cures of student attrition. Chicago, IL: University of Chicago.

[87] US Department of Education. (2009, June 24). Making college more affordable by simplifying the student financial aid application (FAFSA). Retrieved from http://www2.ed.gov/finaid/info/apply/simplification.html

[88] Vernon-Feagans, L., Garrett-Peters, P., Willoughby, M., \&Mills-Koonce, R. (2012). Chaos, poverty, and parenting: Predictors of early language development. Early Childhood Research Quarterly, 27(3), 339-351.

[89] Walfish, S., \& Watkins, K. M. (2005). Readability level of health insurance portability and accountability act notices of privacy practices utilized by academic medical centers. Evaluation \& The Health Professions, 28(4), 479-486.

[90] Walpole, M. B. (2003). Socioeconomic status and college: How SES affects college experiences and outcomes. Review of Higher Education, 27(1), 45-73.

[91] Walsh, T. M., \&Volsko, T. A. (2008). Readability assessment of internet-based consumer health information. Respiratory Care, 53(10), 1310-1315.

[92] Wang, P., \& Machado, C. (2015). Meeting the needs of Chinese English language learners at writing centers in America: A proposed culturally responsive model. Journal of International Students, 5(2), 143-160.

[93] Ward, L., Siegel, M. J., \& Davenport, Z. (2012). First-generation college students: Understanding and improving the experience from recruitment to commencement. San Francisco, CA: Jossey-Bass.

[94] Weiss, K. D., Vargas, C. R., Ho, O. A., Chuang, D. J., Weiss, J., \& Lee, B. T. (2016). Readability analysis of online resources related to lung cancer. Journal of Surgical Research, 206(1), 90-97. 